Dossiê “Ser criança no Brasil Hoje: (re)invenções da infância em contexto de mudança social"

\title{
Infância e segurança pública: desvelando o medo que crianças de tenra idade possuem do aparato policial
}

\author{
Childhood and public security: unveiling low age children's fear of \\ police apparatus \\ José Ricardo de Souza Rebouças Bulhões ${ }^{1}$ \\ João Diogenes Ferreira dos Santos ${ }^{2}$ \\ Samila da Silva Leite Pita Rebouças ${ }^{3}$
}

Resumo: $\mathrm{O}$ presente artigo apresenta os resultados da pesquisa sobre o medo que crianças, oriundas de um bairro periférico, frequentadores de uma creche pública possuem do aparato policial. No Brasil, conforme determina a Constituição Federal de 1988, as forças policiais são responsáveis pela prevenção da vida, pela repressão ao crime e a manutenção da ordem pública. No entanto, constata-se que há um descontrole das forças de segurança, em que o uso da violência se faz abusiva e o medo se instaura como forma de sociabilidade. As ações virulentas dos policiais que se manifestam em agressões físicas, psicológicas e, até mesmo, em mortes, ocorrem, sobretudo, nos bairros periféricos das cidades brasileiras. Essa violência incide igualmente na população infanto-juvenil. Deste modo, buscou-se compreender como o medo da polícia se manifesta no universo infantil. Pesquisou-se crianças, de 04 a 05 anos de idade, moradoras de um bairro periférico, com maior

\footnotetext{
${ }^{1}$ Doutorando em Memória: Linguagem e Sociedade(2014) pelo Programa de PósGraduação da Universidade do Sudoeste da Bahia(UESB) na Linha de Pesquisa:Memória, Discursos e Narrativas. É pesquisador vinculado ao Grupo de Pesquisa em Análise do Discurso da UESB. E-mail: jrsreboucas@yahoo.com.br

2 Professor titular nível A da Universidade Estadual do Sudoeste da Bahia, pesquisador do Museu Pedagógico e professor do Programa de Pós-Graduação em Memória, Linguagem e Sociedade. E-mail: diovc@uol.com.br

3 Mestre em Memória: Linguagem e Sociedade(2013) pelo Programa de PósGraduação da Universidade do Sudoeste da Bahia(UESB). E-mail: mila762@hotmail.com
}

Latitude, Vol. 10, no 2, pp. 353-381, 2016

DOI: https://doi.org/10.28998/2179-5428.20160208 
José Ricardo de Souza Rebouças Bulhões

João Diogenes Ferreira dos Santos

Samila da Silva Leite Pita Rebouças

incidência de crimes. Elegeu-se o caminho metodológico do estudo etnográfico, considerado apropriado à interpretação da ação nos contextos infantis. Portanto, com base nesta pesquisa, pode-se afirmar que as crianças em tenra idade vivenciam a violência policial, em que o medo se constitui como elemento vivo expresso nas falas e nas brincadeiras infantis.

Palavras-chave: Criança. Medo. Polícia. Violência. Etnografia.

\begin{abstract}
This article presents the results of research on the fear that children, coming from an outlying neighborhood, regulars of a public kindergarten have the police apparatus. In Brazil, as determined by the Federal Constitution of 1988, the police are responsible for preventing life, for the repression of crime and the maintenance of public order. However, it appears that there is a lack of security forces, in which the use of violence is abusive and fear is established as a form of sociability. Virulent actions of the police that manifest themselves in physical, psychological and even deaths occur mainly in the suburbs of Brazilian cities. This violence also focuses on children and adolescents. Thus, we sought to understand how the fear of the police is manifested in the infant universe. Researched up children, 04-05 years of age, residents of a suburb, with a higher incidence of crimes. He was elected the methodological approach of the ethnographic study, considered appropriate to the interpretation of the action in child contexts. Therefore, based on this research, it can be said that children at a young age experience police violence, in which the fear is a living element expressed in the statements and in children's play.
\end{abstract}

Key-words: Child. Fear. Police. Violence. Ethnography.

\title{
1. Introdução
}

No Brasil, é esperada da força policial a garantia da segurança pública e a proteção de todo e qualquer cidadão. Caberia à policia, em última instância, o papel de prevenir, coibir e conter as diferentes formas de violência e criminalidade. No entanto, na história brasileira e na prática das organizações policiais, seu papel e representação social têm sido 
Infância e Segurança Pública: desvelando o medo que crianças de tenra idade possuem do aparato policial

profundamente contraditórios (BAIERL, 2004). Em vez de manter a ordem pública e reprimir o crime, alguns policiais extrapolam o uso da força, utilizando-a de forma desnecessária, inadequada e abusiva. Segundo Pinheiro (1998, p. 183):

Há no Brasil um formidável descompasso entre o texto constitucional, os princípios das convenções internacionais retificadas pelo Brasil - cito apenas a proibição das prisões arbitrarias, da tortura, das execuções sumárias, que constituem práticas regulares em todo o país - e o funcionamento efetivo das policias militares e civis, nos 26 estados. As policias, desde 1985, como em toda a história republicana, existem apenas nominalmente, mas não são instituições eficientes para garantir os direitos democráticos e a segurança [...].

As forças policiais realizam práticas contrárias às normas vigentes no país. Segundo Espinheira (2008) são ações que comprometem o sistema institucional de Segurança Pública. Tais ações presentes no imaginário e cotidiano das pessoas apresentam raízes históricas. Para Stenberger e Cardoso (2005, p. 107), as práticas violentas são provenientes "do ideário de combate ao inimigo, usado desde os anos 1920 em larga escala nas organizações policiais, posteriormente reforçado durante a ditadura militar (1964-1985) com a doutrina da segurança nacional".

Assim, as ações virulentas do aparato policial vêm tecendo ao longo do tempo uma cultura marcada por um histórico de violência. A polícia deixa de incorporar a noção de cidadania e o respeito aos direitos dos cidadãos ao atuar com excesso em sua ação cotidiana. Nesse sentido, Santos (2001, p. 24) ressalta:

O condicionamento social da violência não nos permite negar que haja uma certa cultura policial da violência, até mesmo porque não é toda a sociedade que alimenta a violência nossa de cada dia. As estatísticas do Banco de dados do $\mathrm{MNDH}$ demonstram o quanto a polícia tem sido uma das principais instituições reprodutoras de violência no Brasil, especialmente contra negros e pobres. 
José Ricardo de Souza Rebouças Bulhões

João Diogenes Ferreira dos Santos

Samila da Silva Leite Pita Rebouças

Embora a violência policial afete toda a sociedade, é nas camadas das classes econômicas mais baixas que os abusos e os excessos se manifestam com mais frequência. De acordo com Bandeira e Suarez (2001, p. 78), “o uso da violência para a manutenção da ordem pública se configura como uma forma de discriminação de pobres e não brancos". Salienta Espinheira (2008, p. 48) que:

As desigualdades sociais são institucionalmente reconhecidas. Não há o mesmo tratamento para os diferentes. Uma parcela muito ampla da sociedade é frágil por carências; outra, bem menor, teme pelo que possui. Sem reciprocidade e sem encontro, a própria sociedade se torna objeto do medo e medrosa age irracionalmente sem controlar-se, disseminando o medo como paranoia urbana contemporânea.

As pessoas oriundas de bairros populares se tornam, na atuação policial, alvo dos mais variados abusos e do rol de ações violentas. As polícias criam um perfil criminoso, levando a crer que pessoas da periferia são potencialmente perigosas. Nesse sentido, Pinheiro (1998, p. 49) destaca que "a polícia e outras instituições do sistema de Justiça penal tendem a agir como guardas de fronteira, protegendo dos pobres as elites e exercendo literalmente o papel de cordão sanitário".

Percebe-se que, embora o descontrole da máquina policial perpasse por toda a sociedade brasileira, são nas camadas sociais de baixo poder aquisitivo que esse fenômeno se manifesta de forma mais intensa. Espinheira (2008, p. 31) sublinha que "nas sociedades urbanas contemporâneas a pobreza é fator contribuinte causal da violência, em que o estado de carência limita, frustra e revolta", sendo a violência policial um de seus desdobramentos.

Toda essa truculência e práticas violentas efetuadas pela polícia acabam disseminando o medo ${ }^{4}$ nas camadas sociais mais pobres. Caldeira

${ }^{4}$ Dias (2007, p. 16) ao abordar a questão do medo presente em nossa sociedade afirma que "o medo social é produto de relações de poder desequilibradas, em 
Infância e Segurança Pública: desvelando o medo que crianças de tenra idade possuem do aparato policial

(2000) afirma que a violência e o medo combinam processos de mudanças, alterando a arquitetura urbana, segregando e discriminando grupos sociais em enclaves fortificados.

O excesso e a ilegalidade na prática policial faz surgir o que estudiosos do tema chamam de medo social. Espinheira (2008), Silva (2001), Pinheiro (1998), Alves (1998) e Baierl (2008) afirmam que existe na sociedade brasileira uma cultura do medo. Nessa realidade, o medo da polícia se substancia tornando-se uma ameaça à população de baixa renda. Em relação ao medo que a população periférica sente do aparato policial, concluiu Baierl (2004, p. 145):

É o medo social instituído como instrumento de subjugar e ameaçar as pessoas, mantendo-as sob domínio e controle social. Trata-se do medo decorrente do poder fardado. É um medo que intimida, subjuga e oprime as pessoas, e se relaciona com as forma de ameaça constante, baseado em interesses próprios e particulares de policiais, que utilizam o medo e o seu poder de polícia para extorquir ganhos dos criminosos e de moradores de favelas em troca de favores. Já os moradores de bairros de classe média demonstram esse medo de forma diferenciada. Trata-se do medo de sofrer agressões da polícia de forma indiscriminada e não ser respeitado em seus direitos de cidadania, ou

qualquer dos campos da ação humana, havendo atores que dele mais beneficiam, e outros que por ele se deixam dominar. E a prevalência desta emoção nas estruturas de relações sociais faz-se pela manutenção de uma ordem, cujos vigilantes procuram assegurar a máxima eficiência da sua atuação, podendo estes revestir as mais diversas expressões, formais e informais, para garantirem a sua eficácia no tecido social. Neste sentido, o medo social emana de diferentes fontes, e não é produto de uma espontaneidade ingênua. Ele resulta de uma intencionalidade, que se pode caracterizar por uma maior ou menor intensidade junto daqueles que constituem o alvo preferido de quem da sua insegurança pode beneficiar. Esta emoção reflete estados de insegurança que radicam naquilo que de mais profundo existe no ser humano, e quem mais dela fizer uso maior possibilidade terá de controlar a ação dos outros". 
José Ricardo de Souza Rebouças Bulhões

João Diogenes Ferreira dos Santos

Samila da Silva Leite Pita Rebouças

seja, se envolver em conflitos para os quais não foi convidado. Aqui também a noção de não ser reconhecido em seus direitos, podendo também ser confundido com um marginal ou criminoso. No entanto, não faz parte do cotidiano destes últimos, as ameaças e o terror.

A existência desse medo social, principalmente no que se refere aos moradores das comunidades empobrecidas que convivem com a violência policial, sofre interferências significativas, principalmente na vida dos jovens. Os fatos vividos com frequência na comunidade e o sentimento destes frente às ações policiais são fatores motivadores para a pesquisa no campo infantil dentro do contexto de crianças oriundas de um bairro periférico.

As crianças vivenciam no cotidiano as relações estabelecidas entre a polícia e os demais moradores do bairro, sejam nas ruas, em suas casas, nos estabelecimentos comerciais ou em outros espaços. Tais relações são entremeadas por medo e insegurança pois, na grande maioria das vezes, as ações policiais se configuram nas várias formas de violência. Neste contexto, os moradores de tenra idade convivem com o medo da figura policial.

Geralmente, os medos nascem de avaliações do perigo, como a probabilidade de ser mordido por um cão, ou são desencadeados por eventos, quando uma criança que foi atropelada por um carro tem medo de atravessar a rua. "Crianças que sobrevivem a um terremoto, sequestro ou a algum outro evento assustador podem ter medo de que isso aconteça novamente" (PAPALIA, OLDS e FELDMAN, 2009, p. 305).

Nesse sentido, a partir das experiências presenciadas pelas crianças é comum que elas desenvolvam medos e ansiedades, todos gerados a partir de um determinado estímulo, muitas vezes associados à preservação, às respostas de defesa e, até mesmo, à aprendizagem.

Os medos na infância são bastante imprevisíveis e há, em todas as faixas etárias, acentuadas diferenças individuais quanto à suscetibilidade ao medo. $\mathrm{O}$ 
Infância e Segurança Pública: desvelando o medo que crianças de tenra idade possuem do aparato policial

mesmo estimulo pode ser extremamente ameaçador a uma criança e, ao mesmo tempo, deixar completamente indiferente uma outra. A criança pode, além disso, ser bastante perturbada por um certo estímulo em uma determinada situação, não lhe dando qualquer atenção em outras circunstancias (MUSSEN, CONGER e KAGAN, 1977, p. 322)

Desta forma, a pesquisa objetivou analisar o medo presente em relação à polícia no período denominado de "primeira infância". O local escolhido para a pesquisa encontra-se na periferia da cidade de Vitória da Conquista - BA, em uma comunidade marcada pela presença constante da polícia devido ao trabalho de combate ao tráfico de drogas e outros crimes. As crianças desta localidade vivenciam diariamente a presença policial nas ruas, estabelecimentos e casas. Elas observam os comportamentos, muitas vezes conhecidos, e refletem nessa vivência as suas reações.

Não é raro que figuras desconhecidas provoquem medo. Mas, se a criança se acostuma gradativamente às figuras, origina-se nela uma mistura de sentimentos de medo, curiosidade e divertimento. (MULLER, 1977, p. 66)

Por esse motivo, o foco de análise da pesquisa foi um dos espaços de socialização da criança. Foram selecionadas 40 crianças, com idades entre 04 e 05 anos, frequentadoras da creche local. Assim, o propósito desse trabalho é analisar se crianças de 04 a 05 anos de idade, moradoras de um bairro periférico da cidade de Vitória da Conquista - BA vivenciam no seu cotidiano o medo da polícia. Buscou-se identificar fatores sociais e associálos às vivencia infantis na comunidade, em um processo de interface entre a ação policial no Bairro pesquisado e o medo em análise.

\section{Da metodologia utilizada na pesquisa}

No final do século XX, Corsaro (1997, p. 95) já assinalava que "crianças estão merecendo estudos como crianças". Tal afirmação, segundo Delgado e Muller (2005, p. 3), se dá em razão de que durante muito tempo utilizou-se concepções teóricas que marginalizavam a criança e a infância.

Fernandes e Tomás (20011, p. 2) apresentam os desafios metodológicos nas pesquisas com crianças em dois planos: o teórico, no 
José Ricardo de Souza Rebouças Bulhões

João Diogenes Ferreira dos Santos

Samila da Silva Leite Pita Rebouças

qual se sustenta "a participação das crianças enquanto princípio para a consolidação da sua imagem enquanto sujeito ativo de direitos, atores sociais com espaço na sociedade" e o metodológico, em que se deve ultrapassar o legado epistemológico do déficit da racionalidade e competência das crianças, considerando-as "enquanto objeto de investigação autônomo e independente, enquanto sujeito de um processo de pesquisa, onde a sua voz e ação social são susceptíveis de serem analisadas a partir dela mesma".

Uma estratégia de pesquisa no terreno que pretenda realizar trabalhos empíricos com crianças depara-se com um conjunto de preocupações específicas, tendo em conta as características particulares destes observáveis. É importante que a construção das técnicas seja elaborada com base em ferramentas metodológicas que procurem ser permeáveis às especificidades do grupo social da infância e às particularidades de cada criança enquanto ator social pleno. (SARAMAGO, 2001, p.13)

Assim, embasado em estudos e métodos utilizados por Corsaro (1997), Sarmento (2005) e Delgado e Muller (2005) para a atividade de pesquisa, o caminho metodológico escolhido foi o estudo de caso etnográfico, considerado apropriado à interpretação da ação nos contextos infantis. Esse tipo de investigação tem, para Sarmento (2005, p. 152), “uma perspectiva interpretativa e crítica e que se centra nos fenômenos simbólicos e culturais das dinâmicas de ação no contexto organizacional das crianças". Uma pesquisa com orientação etnográfica incorpora os pressupostos que a constituem, utilizando de pressupostos teóricometodológicos das Ciências Sociais para o conhecimento de uma realidade. Neste sentido, aduz Delgado e Muller (2005, p. 9):

A etnografia visa apreender a vida, tal como ela é cotidianamente conduzida, simbolizada e interpretada pelos atores sociais. A vida é, portanto, plural nas suas manifestações, imprevisível e ambígua nos seus significados. Isso nos desafia a renunciar definição de critérios universais de verdade, assim como nos instiga a pensar nas 
Infância e Segurança Pública: desvelando o medo que crianças de tenra idade possuem do aparato policial

crianças como capazes de interpretar e dar novos sentidos às relações que experimentam com $o$ mundo, com outras crianças e adultos. Nos estudos etnográficos analisamos os aspectos simbólicos e culturais da ação social, os aspectos da existência que se revelam fundamentais na interpretação dos enunciados, as emoções e os sentimentos; como as pessoas envolvidas no estudo atribuem sentidos para os fatos da vida; como interpretam suas experiências ou estruturam o mundo no qual vivem.

Assim, para tentar desvelar o medo que crianças possuem da polícia é essencial observar seus locais, objetos, símbolos, gestos, atividades, comportamentos, interações e situações. Uma presença diária do pesquisador, além de contato direto com as crianças, foi necessária para que se pudesse afirmar que o medo da polícia é manifestado no ambiente escolar. Assim, o método etnográfico revelou-se o mais adequado às pretensões do pesquisador.

A pesquisa apoiou-se em alguns pressupostos teóricos e técnicas do método etnográfico. Adaptações foram necessárias em razão das peculiaridades dos sujeitos pesquisados, isto porque "as crianças se distinguem umas das outras nos tempos, nos espaços, nas diversas formas de socialização, no tempo de escolarização, nos trabalhos, nos tipos de brincadeiras, gostos, nas vestimentas, enfim, nos modos de ser e estar no mundo" (DELGADO e MULLER, 2005, p. 7). Foram escolhidas como técnicas para a captação de dados a observação participante, as atividades em grupo, além de anotações em diário de campo.

Vale dizer que a primeira atitude perseguida no decorrer de todo o trabalho foi a ética. Autores como Delgado e Müller (2005) e Corsaro (1997) evidenciam a necessidade de a questão ética perpassar todas as etapas da pesquisa. Assim, antes de iniciar os trabalhos, foi solicitada a autorização da Coordenação da Creche, professores, pais e dos próprios infantes, entendendo-os como sujeitos de direito. Desse modo, foi garantido à criança, o direito de decidir ou não sobre sua participação na pesquisa.

A inserção do pesquisador no ambiente das crianças pesquisadas aconteceu de forma gradual. Os encontros duraram aproximadamente uma 
José Ricardo de Souza Rebouças Bulhões

João Diogenes Ferreira dos Santos

Samila da Silva Leite Pita Rebouças

hora, durante o período do recreio das crianças. Aos poucos, a presença do pesquisador tornou-se comum, diminuindo a influência no comportamento rotineiro destas. A idéia inicial de observar as crianças em seu cotidiano educacional nos primeiros dias de pesquisa deu lugar à observação participativa, ou seja, o pesquisador começou a ficar onde as crianças estavam (sentado junto às mesinhas, no chão, no parquinho, na cantina, etc.) e a participar das atividades do cotidiano educacional delas.

As crianças sentiram-se à vontade com a presença do pesquisador e contavam, com muita naturalidade, suas experiências de vida. Não foi feita nenhuma pergunta acerca de suas histórias de vida, experiências ou sobre a polícia. Todos os dados relatos e ações das crianças apresentadas na pesquisa surgiram e se manifestaram naturalmente, sem qualquer tipo de induzimento.

Quando foi percebida a confiança das crianças no pesquisador e o início de uma integração deste com o ambiente dos infantes foi realizada uma atividade em grupo. Inicialmente com as crianças de 04 anos e posteriormente com as crianças de 05 anos foi realizada uma atividade de classe elaborada juntamente com as professoras que consistia em contar uma história e depois utilizar o desenho. A orientação inicial foi em não induzir as crianças, nem questioná-las acerca de suas histórias e experiências de vida.

\section{Arcabouço teórico e análise de dados}

A fim de compreender a análise realizada na presente pesquisa é essencial a discussão acerca do período infantil em que se encontram as crianças pesquisadas, além da análise do próprio local em que estão inseridas.

A creche é vista como um ambiente novo para elas, um espaço de socialização onde adquirem características de personalidade e de comportamento consideradas apropriadas ou aceitáveis pela sociedade. Apesar disso, elas levam padrões de comportamento e motivos valorizados por seu próprio grupo, seja ele a família ou a comunidade.

Em grande medida, a cultura na qual a criança cresce prescreve tanto o conteúdo quanto os 
Infância e Segurança Pública: desvelando o medo que crianças de tenra idade possuem do aparato policial

métodos de socialização, tanto o modo como deverá ser treinada, como as características de personalidade, motivos, atitudes e valores que deve adquirir (MUSSEN, CONGER e KAGAN, 1977, p. 304-305).

As crianças desse ambiente da educação infantil possuem características importantes e de enfoque necessário para a compreensão posterior de todo o processo de descobertas na análise da pesquisa realizada. Essas crianças estão na fase do desenvolvimento geralmente chamada de idade pré-escolar, fase caracterizada por Piaget (1999) como período pré-operatório. Piaget (1999, p. 42) afirma que durante este período as crianças desenvolvem a capacidade de criar símbolos e utilizá-los nas atividades do dia-a-dia.

Enderle (1994, p. 75) conceitua este período como fase mágica, dada a predominância do pensamento fantástico que tanto caracteriza a infância, ainda que a fantasia não persista ao longo de toda a fase que vai do segundo ao sexto ano de vida. Nessa fase, o processo de desenvolvimento é dirigido e interferido por diversas variáveis, entre elas o nível socioeconômico, educacional e fatores externos à própria criança, ou à dinâmica da família. Dessa maneira, os encadeamentos e influências sociais ocorrem a todo o momento, dando condições para o aparecimento de determinados comportamentos e impondo limitações para a manifestação destes (SOUZA e MARTINS, 2005).

Nessa fase peculiar, a criança tenta descobrir o sentido do mundo lidando com objetos e pessoas. Ela constrói estruturas mentais e adquire modos de funcionamento em função da tentativa incessante de entender o mundo ao seu redor, de compreender o que acontece e de sistematizar as suas ideias. Ao mesmo tempo, recebe influências do seu meio e leva isso para os espaços de socialização de diferentes maneiras.

Na educação infantil os medos são manifestados no comportamento da criança em situações de interação no lar, na escola, no local de brincadeiras, etc. A imaginação, a palavra, o desenho são instrumentos que a criança tem para se relacionar com o mundo físico e social, permitindo que ela use experiências para explicar e reproduzir a sua vivência.

A criança mergulha no mundo da percepção, da comunicação, da forma, da abstração, da inteligência, do pensamento, no meio escolar e por 
José Ricardo de Souza Rebouças Bulhões

João Diogenes Ferreira dos Santos

Samila da Silva Leite Pita Rebouças

meio do processo lúdico evidente nela. Seu desenvolvimento mental e intelectual se expressa principalmente por meio da linguagem verbal. Isso revela a importância inicial da comunicação direta com a criança na análise dos seus medos, já que diz respeito a ela e aos seus interesses.

A conquista da linguagem expressa o pensamento da criança. Ela promove mudanças, principalmente no modo de se relacionar com o seu meio, possibilita novas formas de comunicação com os indivíduos e organiza seu modo de agir e pensar. A fala, por exemplo, expressa a capacidade que a criança, nesta faixa etária, está adquirindo para exprimir e representar seus pensamentos. Esses instrumentos compõem o seu desenvolvimento intelectual, moral e social.

O pensamento da criança de 04 e 05 anos de idade se instala cada vez mais no sistema ordenado constituído pela língua falada por sua roda, ganhando, graças a esta, coerência, clareza e comunicabilidade. A língua impõe, de certo modo, suas exigências sociais e culturais ao pensamento, simultaneamente, segundo dois sistemas diferentes parece ser proeza dificilmente realizável e, sem dúvida, pouco proveitosa, ao menos para a maior parte dos indivíduos (OSTERRIETH, 1974).

A criança deste período pensa como pode, aprende o real diferentemente dos adultos; não tem, todavia, as possibilidades de abstração e de imaginação que lhe permitam uma 'concepção do mudo' ou a construção de uma cosmologia, fosse embora artificialista ou animista. Está, aliás, muito ocupada em viver para construir sistemas. (OSTERRIETH, 1974, p. 120)

Torrance (1976, p. 108) salienta que na faixa etária de quatro e cinco anos de idade a criança aprende papéis tipicamente de adultos, levando sua curiosidade a procurar o verdadeiro e o certo. É o período em que "a criança é capaz de relacionar os acontecimentos isolados, embora possa não compreender a razão da relação. Nessa idade, começa a ter consciência dos sentimentos alheios". Neste contexto, Jersild (1977, p. 290) elenca alguns fatores que podem contribuir para a susceptibilidade da criança ao medo. 
Infância e Segurança Pública: desvelando o medo que crianças de tenra idade possuem do aparato policial

A fraqueza e incapacidade física do infante às exigências da vida cotidiana são, em alguns casos, condição para o surgimento de medo. Ações e fatos que reduzam a confiança da criança em si mesma, que a envolva em situações nas quais se sinta insegura, ou que a ameace ou a coloque em conflito ou remorso, aumentam sua susceptibilidade ao medo. A relação das próprias crianças com seus pais, parentes ou adultos próximos, podem fazer surgir medo, pois por meio de manifestações evidentes ou sutis de seus temores, podem os adultos não apenas sugerir à criança a presença do perigo, como pode enfraquecer sua convicção de segurança ou proteção.

Na coleta de dados, evidenciamos que alguns sentimentos e medos dos adultos são conhecidos e compartilhados pelas crianças. Conforme os relatos abaixo:

Quando a polícia esteve em minha casa eu não tive medo, só a minha mãe. (criança 17,4 anos)

Minha mãe tem medo das polícia e tá morando na roça pras polícia não achar ela [...] A mãe Dida tem medo das polícia porque usa droga. (criança $31-5$ anos).

Assim, notou-se que muitos dos temores das crianças em relação à polícia decorrem dos sentimentos e acontecimentos vividos pelo grupo social em que os infantes estão inseridos. A noção de polícia compreendida pelas crianças pesquisadas torna-se compartilhada, influenciada e apreendida pelo que Pollack (1992, p. 201) chama de "vividos por tabela", ou seja, são acontecimentos vividos por outros, mas que entendem elas mesmas terem sentido e presenciado.

Nesse sentido, o sentimento surgido dentro de uma coletividade traz a memória como algo indissociável de um grupo. Por meio desta, os 
José Ricardo de Souza Rebouças Bulhões

João Diogenes Ferreira dos Santos

Samila da Silva Leite Pita Rebouças

fatos integrantes do grupo são transmitidos e sociabilizados, tornando-se pertencentes a ele, mesmo que não vivenciados.

Podemos, portanto dizer que a memória é um elemento constituinte do sentimento de identidade, tanto individual como coletiva, na medida em que ela é também um fator extremamente importante do sentimento de continuidade e de coerência de uma pessoa ou de um grupo em que sua construção de si. (POLLAK, 1992, p. 204)

Os fatos que ocorrem no bairro afetam e chamam a atenção das crianças. As falas dos infantes demonstram sua atenção e percepção aguçada das ações policiais em suas comunidades:

Tio, Vinícius foi preso. É porque ele tinha droga. [...] Dondom e Gabriel já foram presos. [...] Gabriel morreu porque deu dedo pras polícia [...] A polícia bota no pau, bate. Você já viu batendo? vi duas polícia na moto matar quatro, Dondom e Vinícius e pegou no pau e bateu neles (criança $32-5$ anos)

As polícias estão dando tiros no mato. (criança 28 5 anos)

Vi a polícia prender os bandidos. (criança $39-5$ anos)

A polícia mandou meu tio guardar a moto [...] a polícia chegou, rodou, foi no México e apontou a arma [...] a polícia noutro dia matou um ladraozin pequeno [...] jacaré estava correndo da polícia com droga e a polícia foi atrás dele (criança $14-4$ anos) 
Infância e Segurança Pública: desvelando o medo que crianças de tenra idade possuem do aparato policial

A polícia prendeu meu tio porque ele estava batendo nas meninas. (criança $12-4$ anos)

Pode-se compreender que, na maioria das vezes, mesmo não tendo contato direto com policiais, estes tornam-se figuras conhecidas na memória das crianças pesquisadas, pois os infantes estão atentos aos acontecimentos vividos dentro do bairro e às reações das pessoas próximas. Neste sentido, Pollack (1992, p. 201) ressalta que:

A memória é constituída por pessoas, personagens. Aqui também podemos aplicar o mesmo esquema, falar de personagens realmente encontradas no decorrer da vida, de personagens frequentadas por tabela, indiretamente, mas que, por assim dizer, se transformaram quase que em conhecidas, e ainda de personagens que não pertenceram necessariamente ao espaço-tempo da pessoa.

Os policiais são personagens conhecidos das crianças. As falas, os gestos e práticas características da polícia são conhecidos e reproduzidos a todo o momento pelos infantes em seu ambiente social. Embora, muitas vezes, não tenham o contato direto com policiais, as crianças observam a atuação, seus modos de agir e práticas rotineiras, de acordo com o que ouvem ou veem de pessoas próximas a elas. Desta forma, conseguem reproduzir com exatidão e detalhes as práticas policiais.

Aqui no bairro a policia põe na parede com a perna aberta para revista (criança 31 - 5 anos)

Se recorrermos aos ensinamentos de Pollack (1992), em especial ao que se refere à psicologia social, percebemos que a imagem dos policiais está inserida no próprio sentimento de identidade dos infantes. As ações e os acontecimentos referentes à atuação da polícia no bairro são naturalizados e aceitos como normais, inerentes ao próprio ambiente em que estão inseridos. 
José Ricardo de Souza Rebouças Bulhões

João Diogenes Ferreira dos Santos

Samila da Silva Leite Pita Rebouças

\begin{abstract}
Nessa construção da identidade - e aí recorro à literatura da psicologia social, e, em parte, da psicanálise - há três elementos essenciais. Há a unidade física, ou seja, o sentimento de ter fronteiras físicas, no caso do copo da pessoa, ou fronteiras de pertencimento ao grupo, no caso de um coletivo; há a continuidade dentro do tempo, no sentido físico da palavra, mas também no sentido moral e psicológico; finalmente, há o sentimento de coerência, ou seja, de que os diferentes elementos que formam um indivíduo são efetivamente unificados. De tal modo isso é importante que, se houver forte ruptura desse sentimento de unidade ou de continuidade, podemos observar fenômenos patológicos. Podemos portando dizer que a memória é um elemento constituinte do sentimento de identidade, tanto individual como coletiva, na medida em que ela é também um fator extremamente importante do sentimento de continuidade e de coerência de uma pessoa ou de um grupo em sua reconstrução de si. (POLLACK, 1992, p. 205)
\end{abstract}

Assim, a polícia se efetiva como referência na vivência dos infantes pesquisados, pois a construção de suas identidades é produzida em referência aos fatos e pessoas próximas às crianças. Os conflitos entre policiais e moradores do bairro acabam afetando e construindo os valores e as percepções das crianças, manifestando-se das mais variadas maneiras.

Em diversos momentos da pesquisa observa-se a ação das educadoras chamando a atenção dos infantes com a utilização de termos como: "Se não parar vou chamar a polícia" ou "Vou chamar a polícia, vai continuar?". Assim, apesar do ambiente escolar ser diferenciado, percebese que as experiências e o medo social transpassam os muros da escola, sendo refletidos nas conversas, brincadeiras e imitações da realidade vivida. Vale frisar que as práticas e ações das polícias geram em algumas dessas crianças sentimentos negativos de aversão, decorrentes de experiências vividas por pessoas próximas a elas. 
Infância e Segurança Pública: desvelando o medo que crianças de tenra idade possuem do aparato policial

Queria por fogo nas polícia porque eles matou meu pai e bateu em dona Deti (criança $12-4$ anos)

Meu pai falou que ia matar as polícia (criança $21-4$ anos)

Quero ser matador de polícia (criança 14 - 4 anos)

\subsection{As manifestações expressas por intermédio das falas}

Como visto, as falas das crianças vêm carregadas de sentimentos e demonstram capacidade de recontar a realidade. Na fase da pré-escolar, a fala passa a ocupar um lugar privilegiado como instrumento de comunicação. As crianças participam de diálogos, fazem perguntas e respondem.

Nas rodas de conversas, método utilizado na creche para contar histórias, a atenção da criança fica totalmente voltada para a professora, que utiliza em sua prática diversas estratégias que entoam emoção à história, como o tom de voz, a mudança da fala dos personagens e, ao mesmo tempo as interações, onde as crianças tornam-se participantes das narrativas.

As intervenções feitas pelas crianças expressam a capacidade e a necessidade que elas têm de exprimir e representar os seus pensamentos.

Quero ser federal, polícia federal (criança $15-4$ anos)

As polícia viu as drogas e matou (criança $32-5$ anos)

Os bandidos se escondem no mato para fugir das polícia (criança $31-5$ anos)

Nas falas das crianças a polícia sempre aparece relacionada à morte, fuga, violência, poder e maldade:

A polícia é pra matar [...] A polícia mata por causa de 'cocada' [...] A polícia mata [...] A polícia mata, 
José Ricardo de Souza Rebouças Bulhões

João Diogenes Ferreira dos Santos

Samila da Silva Leite Pita Rebouças

depois prende e pega as drogas. [...] As balas das polícia quando atira pega nos pés [...] No Aparecida a polícia vai também e lá mata (criança $32-5$ anos)

A cara da polícia é de mal. (criança 21- 4 anos)

A polícia chegou para roubar a arma (criança $14-4$ anos)

A polícia mata ladrão (criança $39-5$ anos)

A polícia bate também [...] A policia mata por causa de droga, prende (criança $38-5$ anos)

A polícia pega coisa do outros (criança 36 - 5 anos)

Os homens correm e a polícia prende (criança $31-5$ anos)

Muitas das falas refletem o medo que as crianças possuem do aparato policial. $\mathrm{O}$ temor de estar perto de um policial evidencia-se em alguns relatos delas:

A polícia chegou e eu fiquei parada porque não podia me mexer (criança $12-4$ anos)

Fui comprar R\$ 1 real de pão, vi “duas polícia" e me escondi atrás do carro. (criança $31-5$ anos)

Quando a polícia chega agente corre porque se não a polícia pega (criança $32-5$ anos)

Embora o temor da polícia se manifeste em muitas das falas das crianças, com base nas narrativas, infere-se o desejo de se tornar policial. 
Infância e Segurança Pública: desvelando o medo que crianças de tenra idade possuem do aparato policial

\author{
Quero ser policial (criança 28 - 5 anos) \\ Todos nós 'quer ser polícia' (criança 17 - 4 anos) \\ Quero ser federal, polícia federal (criança $15-4$ \\ anos)
}

Quando perguntado pela professora na turma de 05 anos sobre quem gostaria de ser policial, as crianças 28 e 32 se manifestaram positivamente, frisando que a infante 32 aduziu que gostaria de ser policial "para matar gente".

Vale dizer que os jargões policiais são comuns nas falas das crianças. Elas reproduzem o que ouvem de pessoas próximas.

Olha meu revolver, olha o tamanho da bicha (criança $21-4$ anos)

Mão na cabeça [...] Cala boca, abre as pernas (criança $32-5$ anos)

Você esta preso! (criança $36-5$ anos)

Percebe-se que o papel da segurança pública exercida pela polícia não perpassa na mente das crianças. Em nenhum momento das observações pode ser visto ou ouvido de qualquer criança dizer que a polícia protege ou cuida. Em determinado momento a professora da turma de 05 anos pergunta: "Quem nos protege aqui na terra?" e as crianças respondem: "Deus".

O temor em algumas crianças é mais evidente do que em outras. Enquanto algumas querem ser como policiais, outras se manifestam no sentido de rechaçar o aparato policial militar.

Não quero ser policial porque não gosto de polícia (criança $12-4$ anos)

Na turma de 04 anos, ao ouvir uma história onde dizia que o sonho de um ratinho (personagem da história) era ser policial, a criança 21 se 
José Ricardo de Souza Rebouças Bulhões

João Diogenes Ferreira dos Santos

Samila da Silva Leite Pita Rebouças

manifestou dizendo "tenho pena dele". Os relatos demonstram que as crianças recontam os fatos à sua maneira e tentam compreender o mundo físico e social que as cercam como fatos comuns à sua realidade. Todas essas expressões são produtos de uma perspectiva particular e de um modo próprio de seu pensamento.

Ao utilizar a linguagem dentro de um processo de comunicação social, as crianças expressam na fala as suas necessidades e carregam experiências com a representação policial dentro da vivência coletiva.

Assisti-se durante a primeira infância a uma transformação da inteligência que, de apenas sensomotora ou pratica que é no inicio, se prolonga doravante como pensamento propriamente dito sob a dupla influencia da linguagem e da socialização. A linguagem, permitindo ao sujeito contar sua ações, fornece de uma só vez a capacidade de reconstituir o passado, portanto, de evocá-lo na ausência de objetos sobre os quais se referiam as condutas anteriores, de antecipar as ações futuras, ainda não executada, e até substituí-las, às vezes, pela palavra isolada, sem nunca realizá-las (PIAGET, 1991, p. 19-20)

As circunstâncias do meio em que elas vivem, somadas às condições de sua realidade, apresentam insegurança e medo ao aparato policial, sejam nas expressões que rechaçam a polícia, nas imitações e reproduções do papel policial, ou até mesmo, ao expressar o desejo de serem policiais. Em suas falas, a polícia sempre está ligada a violência e poder. O sentimento de que tudo é possível quando se torna policial é evidente nas falas das crianças.

\subsection{As manifestações expressas por intermédio dos gestos}

Toda a situação imaginária das crianças contem regras de comportamento condizentes com o que é apresentado para elas. Ao criar, 
Infância e Segurança Pública: desvelando o medo que crianças de tenra idade possuem do aparato policial

utilizam vários símbolos que servem de representação da realidade. Um desses símbolos pode ser verificado nas brincadeiras.

Durante a realização da pesquisa, a criança 32 encosta no pesquisador e diz: "'Nóis' é polícia!" e sai correndo atrás da criança 38 para simular uma "prisão". A criança 32 põe a criança 38 de cara para a parede e simula uma revista policial. A criança 32 dá tapas na cabeça e chutes nas pernas da criança 38 . A criança 32 continua simulando ser policial e grita com a criança 38: "Pede desculpas", repetidamente. Nesse momento, expressa uma forte tendência característica desta fase: a fusão muito íntima entre o significado da realidade e o que é visto por ela.

As crianças se esforçam para desempenhar com fidelidade aquilo que observam, como afirma Vygostky (1984, p. 117), "na brincadeira, a criança sempre se comporta além do comportamento habitual de sua idade, além de seu comportamento diário: na brincadeira é como se ela fosse maior do que é na realidade".

Em outro momento, as crianças 21 e 34 simulam portar uma arma e atiram na criança 32. Momentos depois, a criança 32 coloca suas mãos para trás, simulando estar algemada e fica com o rosto voltado para a parede. As atitudes, as ações e os gestos reproduzidos na brincadeira tornam-se relações naturalizadas e demonstram a intimidade e o conhecimento delas com os comportamentos da polícia em sua comunidade.

Durante as observações no pátio, presenciam-se todos os dias as brincadeiras que trazem referências à polícia. Em determinada situação, a criança 32 fica brincando e gritando: “Foge, foge que a polícia chegou!". Em outra, a criança 34 corre atrás das meninas com uma arma de brinquedo dizendo que "vai prender" todas elas.

Durante um momento do recreio observa-se a reação da criança 39 ao dar um tapa na criança 21 e simular um revólver com o dedo, apontando para o mesmo. Em outra situação, durante as brincadeiras no pátio, as crianças de 04 anos corriam em círculos gritando: "Corre, corre que a polícia vai matar!" Quase todas, em algum momento, simularam portar armas usando as próprias mãos.

O papel e a influência que a polícia tem no imaginário das crianças pesquisadas são claros e evidentes. Em determinado momento as crianças de 05 anos encenam uma abordagem policial. Algumas seguram a criança 32 e dizem que vão prendê-la. Ela corre dos meninos, enquanto estes tentam "capturá-la". Em outra situação, a criança 34 simula um revólver 
José Ricardo de Souza Rebouças Bulhões

João Diogenes Ferreira dos Santos

Samila da Silva Leite Pita Rebouças

com o dedo e corre atrás dos colegas, imitando o som de uma sirene de viatura policial.

A associação ao medo e a apreensão à força policial está presente não somente nas ações cotidianas como também na escolha das brincadeiras na escola. Como exemplo destaca-se uma determinada situação onde a criança pedala um brinquedo e simula uma sirene de uma viatura policial fazendo com que toda a turma corra dela. O que num primeiro momento parece uma simples ação lúdica é um ato de imitação e de reação a determinado fato que a deixou num estado apreensivo ou de real medo.

No ato de brincar as crianças criam suas regras, lapidam comportamentos e fazem desta interação um jogo. “O jogo, então, é uma função do ego, uma tentativa, no sentido de sincronizar os processos corporais e sociais do eu". (ERIKSON, 1976, p. 194)

Nesses processos lúdicos, observa-se a interiorização da imitação utilizada como forma de reprodução de um modelo e de movimentos dos outros, através de simbologias, gestos, palavras e sentimentos.

É pela imitação diferida que se efetua a passagem da inteligência sensório-motora para a inteligência representativa. Ao ser a imitação interiorizada, as imagens elaboram-se e tornam-se, ceteris paribus, como que os substitutos interiorizado dos objetos dados à percepção. O significante é então dissociado do significado e elabora-se o pensamento representativo. (DOLLE, 1995, p. 93)

Para chegar a este momento da imitação as crianças criam a identificação. Este conceito refere-se ao processo que leva-as, inicialmente de maneira inconsciente, a sentirem e comportarem como autoras de certas características que, na verdade, são de outras pessoas.

A identificação, portanto, é um processo hipotético que leva as crianças a adotarem alguns padrões comportamentais integrados $\mathrm{e}$ complexos, atributos e características pessoais, além dos motivos do modelo. Além disso, as respostas adquiridas por intermédio da 
Infância e Segurança Pública: desvelando o medo que crianças de tenra idade possuem do aparato policial

identificação parecem ser espontaneamente emitidas, sem qualquer treino específico e recompensa direta pela imitação, sendo geralmente estáveis e duradouras até certo ponto e não passageiras. (MUSSEN, CONGER E KAGAN, 1977)

É, portanto, indispensável à criança que possa dispor igualmente de um meio de expressão própria, isto é, de um sistema de significantes construídos por ela e dóceis às suas vontades: tal é o sistema dos símbolos próprios do jogo simbólico, tomados de empréstimo à imitação a titulo de instrumentos, mas a uma imitação não procurada por si mesma e simplesmente utilizada como meio evocador a serviço da assistência lúdica: tal é o jogo simbólico, que não é apenas assimilação do real ao eu, como jogo em geral, mas assimilação assegurada (o que reforça) por uma linguagem simbólica construída pelo eu e modificável à medida das necessidades. (PIAGET E INHELDER, 1978, p. 52)

Assim, é evidente que nas brincadeiras as crianças mostrem a sua capacidade de resolver e de receber ajuda para os problemas de sua vida privada. Tais atos mostram os seus desejos, os sentimentos de indignação e também de medo, desejando até mesmo ocupar lugar na polícia. Essa reflexão é apresentada como forma de reprodução do medo que os demais colegas devam ter e, ao mesmo tempo, o dever de respeitar e obedecer a esta figura.

\subsection{As manifestações expressas por intermédio brinquedo}

Outro aspecto importante na expressão infantil, no ambiente de socialização escolar, é a função do brinquedo. Segundo Souza e Martins (2005, p. 181):

O brinquedo é a essência da infância; é o veiculo do crescimento; é o meio extremamente natural que possibilita à criança explorar seu mundo, tanto quanto o do adulto, possibilitando descobrir-se e se 
José Ricardo de Souza Rebouças Bulhões

João Diogenes Ferreira dos Santos

Samila da Silva Leite Pita Rebouças

entender, conhecer os seus sentimentos, as suas ideias e a sua forma de reagir.

Por meio dele, as crianças projetam-se nas atividades dos adultos e procuram coerência com os papéis assumidos. As crianças do grupo analisado fazem o uso de alguns brinquedos na busca exploratória do seu mundo, dos seus sentimentos e ações ligadas à realidade. Neste caso, o velocípede guiado simula um carro de polícia correndo atrás das pessoas (simbolizados pelos colegas de turma), ao pedalar, reproduzem o som da sirene; as peças de brinquedos, a folha, o giz, o lápis viram armas que simulam o combate entre polícia e ladrão, os carrinhos de brinquedo também são usados por elas para simular a ação da polícia.

As crianças criam uma situação ilusória e imaginária como forma de satisfazer seus desejos não realizáveis e, por isso, o brinquedo se caracteriza como útil e real para que elas realizem a ação do mundo dos adultos dentro das suas realidades.

A exposição a modelos humanos que estão se comportando agressivamente tem uma grande influencia para aliciar comportamento agressivo, independente de ser ou não precedida de experiências frustrantes (MUSSEN, CONGER e KAGAN, 1977, p. 312)

Ao fazerem o uso do brinquedo, as crianças o manuseiam como instrumento das suas dramatizações. Desses instrumentos surgem os usos e as circunstâncias compartilhadas por elas no espaço criado pela escola, refletindo também experiências vivenciadas fora do ambiente escolar. Segundo Silva (1994, p. 85):

Brincar para a criança é uma parte intrínseca de sua vida à medida que vai urgindo seu caminho através do tempo e do espaço. Brincar, antes de mais nada, é um processo e não um produto e talvez seja a diferença fundamental entre $\mathrm{o}$ brinquedo $\mathrm{e} o$ 
Infância e Segurança Pública: desvelando o medo que crianças de tenra idade possuem do aparato policial

trabalho. Brincar não é um fim de uma atividade ou o resultado e uma experiência e envolve a participação total do individuo no processo. É um movimento físico, emocional, mental ou a combinação dos três.

Nesse ambiente lúdico, o faz de conta, o brinquedo e a brincadeira demonstram como as crianças experimentam diferentes papéis e funções sociais a partir da observação do mundo dos adultos. A vontade de reproduzir tais papéis está claramente presente no ato de brincar e no brinquedo propriamente. Nessa reprodução, a ação revela desejos, temores, sentimentos, entre outras situações.

Em determinados momentos da pesquisa pode-se observar que, de alguma forma, os brinquedos são utilizados como instrumentos policiais. A criança 28, ao pegar um carro de brinquedo, informa ao pesquisador que o objeto se tratava de um "carro de polícia". Outra criança pega um carro, diz que é da polícia e ameaça: "vou atropelar o povo".

Em outra situação, a criança 13 brinca ao lado do pesquisador com, segundo ela, um "carro de polícia". Já em outro momento a criança 14 simula portar uma arma com uma borracha e "atira" na criança 21.

As reproduções observadas nas brincadeiras das crianças refletem o ambiente sociocultural em que estão inseridas. A imposição do respeito e do medo aos demais infantes relacionam o papel de intimidação e poder da polícia existente em seu imaginário.

\section{Considerações finais}

No Brasil há um conflito entre o que versa a lei e o que é praticado pelas polícias nos estados. Em vez de manter a ordem pública e reprimir o crime, as instituições policiais extrapolam o uso da força, utilizando-a de forma desnecessária, inadequada e abusiva.

Diante desse cenário de descontrole, com o uso da violência excessiva, o medo se instaura como forma de sociabilidade (ESPINHEIRA, 2008). O medo do policial e a ameaça que ele representa, nas palavras de Baierl (2004, p. 198) "é um medo singular-coletivo compartilhado pelos diferentes segmentos da sociedade; é instituído como instrumento de subjugar e ameaçar as pessoas, mantendo-as sob o domínio e o controle 
José Ricardo de Souza Rebouças Bulhões

João Diogenes Ferreira dos Santos

Samila da Silva Leite Pita Rebouças

social". Desse perpasse de práticas violentas e de medo social do aparato policial, advêm a percepção e o aprendizado de crianças que, muitas vezes, mesmo sem o contato direto com a polícia, incorporam os receios, os medos e as inseguranças presentes na coletividade.

Observou-se que há no imaginário das crianças analisadas o receio, a admiração e, em alguns casos, o medo da polícia. Nesse contexto, os acontecimentos vivenciados no bairro tornam-se construções sociais em que as crianças aprendem a se comportar e a temer a figura policial. Tudo isso é devido aos comportamentos, atitudes e conhecimentos que elas adquirem através do contato social. Assim, pode-se dizer que os temores são influenciados também pela aprendizagem. Em virtude da penosa experiência ou de imposições de susto e dominação as crianças podem "aprender" a temer algo ou alguém. Vale dizer que a criança recebe do passado não só os dados da história escrita, mas ela mergulha em suas raízes na história vivida, ou melhor, sobrevivida das pessoas que tomaram parte na sua socialização.

. Importante salientar que, as pessoas que residem num determinado espaço possuem experiências específicas sobre ele, baseadas no conhecimento e na construção que fazem da realidade circundante. Tal experiência, conforme o referido autor, varia desde os sentidos mais diretos e passivos como o olfato, paladar e tato, até a percepção visual ativa e a maneira indireta de simbolização.

Os dados coletados apresentaram muitos símbolos das experiências vividas e percebidas pelas crianças analisadas. Nas falas, nos gestos, nas brincadeiras e nos brinquedos percebeu-se a forte influência que a instituição policial tem nas vidas destas. As crianças, ao exprimirem as suas experiências e noções, revelam como o aprendizado do seu grupo social vem sendo construído, bem como o sentimento de medo é marcado pela presença policial dentro da comunidade.

Os dados coletados transparecem vivências no cotidiano em que o policial é compreendido como um sujeito superior, autorizado a combater, bater e gritar, um indivíduo dotado de autoridade e poder. Em decorrência desse entendimento, muitas práticas e ações policiais são imitadas. $\mathrm{O}$ policial torna-se, para algumas crianças, objeto de desejo e admiração. 
Infância e Segurança Pública: desvelando o medo que crianças de tenra idade possuem do aparato policial

Percebe-se que, através da imitação e reprodução das ações policiais, as crianças demonstram suas capacidades de resolver e de receber ajuda para os problemas sociais. Tais atos mostram os seus desejos e sentimentos ao querer, muitas vezes, ocupar o lugar da polícia, reproduzindo o medo para os demais colegas que devem respeitá-las e obedecê-las.

Assim, apresenta-se de forma clara e evidente o papel e a influência que a polícia tem no imaginário das crianças pesquisadas. As situações imaginárias das crianças contêm regras de comportamento condizentes com o que está representado para elas. Ao criar, utilizam vários símbolos para representar a sua realidade. Nesse sentido, as circunstâncias do meio somadas às condições desta realidade apresentam o medo das crianças em relação ao aparato policial.

\section{Referencias Bibliográficas}

ALVES, Alaôr Caffé. A violência oculta na violência visível: A erosão da lei numa ordem injusta. IN: PINHEIRO, Paulo Sérgio e outros (org.). São Paulo sem medo - um diagnostico da violência urbana. Rio de Janeiro: Garamond, 1998.

BAIERL, Luzia Fátima. Personagens dos medos: decifrando os protagonistas e os coadjuvantes. IN: BAIERL, Luzia Fátima (org.). Medos Sociais - Da violência visível ao invisível da violência. São Paulo: Cortez, 2004.

. Medo Social: dilemas cotidianos. São Paulo: ponto-e-vírgula, 2008.

BANDEIRA, Lourdes e SUAREZ. Mireya. Ordem publica, discriminação e Repressão. In: Violência policial: Tolerância zero?. Goiânia: UFG, 2001.

BRASIL. Constituição. Constituição da República Federativa do Brasil. Brasília, DF, Senado, 1988.

CALDEIRA, T. P. do R. Cidade de muros: crime, segregação e cidadania em São Paulo. São Paulo: EDUSP, 2000.

CORSARO, William A. Sociologia da infância. Tradução de Lia Gabriele Regius Reis. São Paulo: Artmed, 1997.

DELGADO, Ana Cristina Coll; MULLER, Fernanda. Abordagens etnográficas nas pesquisas com crianças. In: CRUZ, Silvia Helena Vieira (Org.). A criança fala: a escuta de crianças em pesquisas. São Paulo: Cortez, 2005.

DIAS, Fernando Nogueira. O Medo Social. Lisboa: Instituo Piaget, 2007. 
José Ricardo de Souza Rebouças Bulhões

João Diogenes Ferreira dos Santos

Samila da Silva Leite Pita Rebouças

DOLLE, Jean-Marie. Para compreender Jean Piaget. Rio de Janeiro: Guanabara Koogan S/A, 1995.

ENDERLE, Carmen. Psicologia do desenvolvimento - o processo evolutivo da criança. 3a edição. Porto Alegre: Artes Medicas, 1994.

ESPINHEIRA, Gey. Sociedade do Medo. Salvador: EDUFBA, 2008.

ERIKSON, Erik H. Infância e sociedade. 2a edição. Rio de Janeiro: Zahar Editores, 1976.

FERNANDES, N.; TOMÁS, C. A participação infantil: discussões teóricas e metodológicas. In: MAGER, M. et al. Práticas com crianças, adolescentes e jovens: pensamentos decantados. Maringá: Editora da UEM, 2011

JERSILD, Arthur T. Psicologia da criança. Belo Horizonte: Itatiaia, 1977.

MULLER, Kurt. Psicologia aplicada à educação. São Paulo: EPU, 1977.

MUSSE, Paul Henry; CONGER, John Janeway; e KAGAN, Jerome. Desenvolvimento e personalidade da criança. $4^{\underline{a}}$ edição. São Paulo: Harbra, 1977.

OSTERRIETH, Paul. Introdução à psicologia da criança. 10 edição. São Paulo: Companhia Editora Nacional, 1974.

PAPALIA, Diane E.; OLDS, Sally Wendkos; e FELDMAN, Ruth Duskin. Desenvolvimento Humano. Porto Alegre: AMGH, 2009.

PIAGET, Jean. A psicologia da Criança. 16º Edição. Rio de Janeiro: Bertrand Brasil, 1999.

- Seis estudos de psicologia. 25a edição. São Paulo: Forense Universitária, 1991.

. e INHELDER, B. A psicologia da criança. $4^{\mathrm{a}}$ Edição. São Paulo: Difel, 1978.

PINHEIRO, Paulo Sergio. Policia e consolidação democrática: o caso brasileiro. IN:

PINHEIRO, Paulo Sérgio e outros (org.). São Paulo sem medo - um diagnostico da violência urbana. Rio de Janeiro: Garamond, 1998.

POLLACK, Michael. Memória e identidade social. Estudos Históricos. Rio de Janeiro, vol. 5, no 10, 1992.

SANTOS, Sales Augusto dos. O direito à vida. In: Violência policial: tolerância zero?. Goiânia: UFG, 2001.

SARAMAGO, Sílvia Sara Sousa. Metodologias de Pesquisa Empírica com Crianças. SOCIOLOGIA, PROBLEMAS E PRÁTICAS, n.ํㅜ 35, 2001. 
Infância e Segurança Pública: desvelando o medo que crianças de tenra idade possuem do aparato policial

SARMENTO, Manuel J. O Estudo de Caso Etnográfico em Educação. In: ZAGO, Nadir; Carvalho, Marília Pinto de; Vilela, Rita Amélia Teixeira (orgs.), Itinerários de pesquisa. Perspectivas qualitativas em sociologia da educação, Rio de Janeiro: DP\&A Editores, 2005.

SILVA, Carla Dornelles da. A atividade Lúdica e a construção do conhecimento. IN: Infância e adolescência em discussão. Fortaleza: NUCEPEC, 1994.

SILVA, Jorge da. Violência policial e ideologia dos algozes-vítima. In: Violência policial: tolerância zero?. Goiânia: UFG, 2001.

SOUZA, Marcia Helena de, e MARTINS, Maria Aurora Mendes. Psicologia do desenvolvimento. Curitiba: IESDE, 2005.

STEINBERGER, Marília; CARDOSO,Ana Izabel. A geopolítica da violência urbana e o papel do Estado. Em: PAVIANI, A.; FERREIRA, I.C.B.; BARRETO, F. F. P. B. Brasília: dimensões da violência urbana. Brasília: Editora Universidade de Brasília, 2005.

TORRANCE, E. Paul. Criatividade - Medidas, testes e avaliações. São Paulo: IBRASA, 1976.

VYGOTSKY, L. S. (1984). A formação social da mente. São Paulo: Martins fontes. 